\title{
Penerapan Algoritma Naive Bayes pada Penentuan Kelayakan Calon Tenaga Kerja Indonesia
}

\author{
Winda Hana Purba1, Poningsih ${ }^{2}$, Dedi Suhendro3 ${ }^{3}$ Irfan Sudahri Damanik ${ }^{4}$, Ilham Syahputra \\ Saragih $^{5}$ \\ Program Studi Sistem Informasi STIKOM Tunas Bangsa Pematangsiantar \\ Jalan Sudirman Blok A No. 1,2,3 Pematangsiantar \\ Email : windahannapurba07@gmail.com
}

\begin{abstract}
Indonesian Manpower is a potential that is a huge potential for the progress of the country. However, the difficulty of employment and the high unemployment rate in Indonesia requires that some people seek perfect employment abroad, in order to improve economic levels. The lack of selection resulted in many problems in the workforce, the low level of education of prospective migrant workers resulted in them having an easy risk on other party tricks, non-violence, unpaid salaries and so on. In accordance with what has been surveyed, it turns out that the sending of these workers is actually not feasible, given the level of education, skills and abilities that are lacking for employment abroad. This study aims to facilitate the government or companies engaged in the field to channel selected workers using the Naive Bayes Method.
\end{abstract}

Keywords: Data Mining, classification, Naïve Bayes Method, employment service, the feasibility of prospective workers.

Abstrak- Tenaga Kerja Indonesia merupakan potensi merupakan potensi yang sangat besar bagi kemajuan negara. Namun susahnya lapangan pekerjaan dan tingginya angka penganguran di Indonesia mengharuskan sebagian orang mencari pekerjaan sempai ke luar negeri, demi meningkatkan taraf ekonomi. Kurang terseleksi nya dengan baik mengakibatkan banyak terjadi nya permasalahan pada tenaga kerja, rendah nya pendidikan calon TKI mengakibatkan mereka menghadapi resiko mudah di tipu pihak lain, Tidak kekerasan, Gaji yang tidak di bayar dan lain sebagai nya. Sesuai dengan apa yang telah di survei, ternyata pengiriman tenaga kerja tersebut sebenarnya kurang layak, mengingat tingkat pendidikan, keterampilan, dan kemampuan yang kurang untuk di pekerjakan ke luar negeri. Penelitian ini bertujuan untuk mempermudah pemerintah atau perusahaan yang bergerak pada bidang ini untuk menyalurkan tenaga kerja yang terseleksi dengan menggunakan Metode Naive Bayes.

Kata kunci: Data Mining, Klasifikasi, Metode Naïve Bayes, Dinas Ketenagakerjaan, Kelayakan Calon Tenaga Kerja.

\section{PENDAHULUAN}

Tenaga Kerja Indonesia (disingkat TKI) adalah sebutan bagi warga negara Indonesia yang bekerja di luar negeri (seperti Malaysia, Timur Tengah, Taiwan, dan Singapore) dalam hubungan kerja untuk jangka waktu tertentu dengan menerima upah. Namun, istilah TKI. Seringkali dikonotasikan dengan pekerja kasar karena TKI sejatinya memang adalah kumpulan tenaga kerja unskill yang merupakan program pemerintah untuk menekan angka pengangguran. Dinas Ketenagakerjaan adalah salah satu lembaga pemerintah yang mempunyai fungsi membina, mengendalikan, melakukan pengawasan dibidang ketenagakerjan, dan 
memeberikan kesempatan kerja secara luas bagi calon pencari kerja. Pada tahun 2017/2018 terdapat 500 jumlah pendaftar calon tenaga kerja indonesia yang ingin bekerja ke malaysia. Dari jumlah terdaftar 300 yang di terrima sebanyak 150 dan 150 calon di tolak dikarenakan tidak memenuhi kriteria yang diinginkan perusahaan. Faktor yang mendorong warga Indonesia bekerja di luar negeri adalah faktor ekonomi. Hal ini dikarenakan tidak adanya akses untuk mendapatkan peluang-peluang kerja. Rendahnya pendidikan dan kualitas calon TKI mengakibatkan mereka menghadapi risiko mudah ditipu pihak lain. Mereka tidak memahami aturan dan persyaratan untuk bekerja di luar negeri. Banyak TKI usianya masih terlalu muda, namun demi kelancaran proses, usia di dokumen dipalsukan. Pemalsuan tidak hanya usia, tetapi juga nama dan alamat. Oleh karena itu, tidak mudah melacak para TKI bermasalah di luar negeri.

Naive Bayes merupakan salah satu metode untuk melakukan klasifikasi, dengan metode Naive Bayes diharapkan data-data calon tenaga kerja tersebut dapat diolah menjadi informasi yang dapat mengklasifikasikan calon tenaga kerja mana yang masuk ke dalam kelompok layak, dan calon tenaga kerja mana yang masuk ke dalam kelompok tidak layak untuk diterima bekerja berdasarkan kriteria-kriteria seperti pendidikan, usia, pengalaman kerja, test kesehatan dan tinggi badan. sehingga bisa menjadi bahan pertimbangan untuk penerimaan calon tenaga kerja yang melakukan pendaftaran tenaga kerja.

\section{METODOLOGI PENELITIAN}

\subsection{Analisa Data}

Dalam melakukan penelitian ini, analisis data yang digunakan adalah data kuantitatif dengan teknik analisis data yang menggunakan jenis statistic deskriptif. Penelitian ini dilakukan di Dinas Ketenagakerjaan Pematangsiantar, Data penelitian diperoleh dengan melakukan wawancara dan observasi kepada pihak instansi. Data yang terkumpul selanjutnya diolah menggunakan algoritma naive bayes. Kemudian diuji dengan tools RapidMiner menggunakan Performance yang berfungsi sebagai validasi dan reabilitas data untuk mencari keakuratan data. Data Penelitian diperoleh dari Dinas Ketenagakerjaan Pematangsiantar. Data yang digunakan dalam penelitian ini adalah Data Tenaga Kerja 2017-2018 yang terdiri dari 66 Data Calon Tenaga Kerja. Berikut adalah data penelitian yang diguakan:

Tabel 1. DATA CALON TENAGA KERJA TAHUN 2017/2018

\begin{tabular}{|l|l|c|l|c|c|c|c|}
\hline No & \multicolumn{1}{|c|}{ Nama } & Usia & Pendidikan & $\begin{array}{c}\text { Tinggi } \\
\text { Badan }\end{array}$ & $\begin{array}{c}\text { Test } \\
\text { Kesehatan }\end{array}$ & $\begin{array}{c}\text { Pengalaman } \\
\text { Kerja }\end{array}$ & Kelayakan \\
\hline 1. & Dwi Ega W & 19 & SLTP & 145 & Sehat & Ada & T. Layak \\
\hline 2. & Denni M & 22 & SLTA & 155 & Sehat & Ada & Layak \\
\hline 3. & Endang S & 30 & SD & 160 & Tidak Sehat & Ada & T. Layak \\
\hline 4. & Irma O & 28 & SARJANA & 157 & Sehat & Tidak Ada & Layak \\
\hline 5. & Anisa D & 27 & SD & 156 & Sehat & Tidak Ada & T. Layak \\
\hline 6. & Agus N & 27 & SARJANA & 159 & Sehat & Tidak Ada & Layak \\
\hline 7. & Dorismauli & 35 & SLTA & 167 & Sehat & Ada & T. Layak \\
\hline 8. & Debi M & 19 & SLTA & 155 & Sehat & Ada & Layak \\
\hline 9. & Roy G & 20 & SLTP & 160 & Sehat & Ada & T. Layak \\
\hline 10. & Jefri & 26 & SLTA & 167 & Sehat & Ada & Layak \\
\hline 11. & Reni O & 26 & SLTA & 173 & Sehat & Ada & Layak \\
\hline
\end{tabular}




\begin{tabular}{|c|l|c|l|c|c|c|c|}
\hline No & \multicolumn{1}{|c|}{ Nama } & Usia & Pendidikan & Tinggi & Test & Pengalaman & Kelayakan \\
\hline$\ldots$ & $\ldots$ & $\ldots$ & $\ldots$ & $\ldots$ & $\ldots$ & $\ldots$ & $\ldots$ \\
\hline 47. & Berliana Si & 22 & SLTA & 156 & Sehat & Ada & Layak \\
\hline 48. & Windi S & 21 & SLTA & 155 & Sehat & Tidak Ada & Layak \\
\hline 49. & Santi Purba & 20 & SLTA & 155 & Sehat & Tidak Ada & Layak \\
\hline 50. & Yosi & 26 & DIPLOMA 3 & 156 & Sehat & Tidak Ada & $?$ \\
\hline 51. & Agus & 26 & SARJANA & 159 & Sehat & Tidak Ada & $?$ \\
\hline 52. & Johan & 25 & SLTP & 155 & TdkSehat & Ada & $?$ \\
\hline 53. & Eka & 24 & DIPLOMA 3 & 167 & Sehat & Ada & $?$ \\
\hline 54. & Cici saragih & 24 & SLTA & 163 & Sehat & Ada & $?$ \\
\hline 55. & Rukia & 39 & SLTA & 160 & Tdk Sehat & Ada & $?$ \\
\hline 56. & Betty & 24 & SLTA & 161 & Sehat & Tidak Ada & $?$ \\
\hline 57. & Anurada & 25 & DIPLOMA 3 & 163 & Sehat & Ada & $?$ \\
\hline 58. & Kristasari & 21 & SLTA & 155 & Sehat & Tidak Ada & $?$ \\
\hline 59. & Esra Yohana & 19 & SLTP & 158 & Sehat & Tidak Ada & $?$ \\
\hline 60. & Fella Indiola & 25 & SLTA & 163 & Sehat & Ada & $?$ \\
\hline 61. & Esti Y & 19 & SLTA & 156 & Sehat & Tidak Ada & $?$ \\
\hline 62. & Amelia & 37 & SLTA & 160 & Sehat & Ada & $?$ \\
\hline 63. & Lenni & 20 & SLTA & 170 & Sehat & Ada & $?$ \\
\hline 64. & Irwan Sari & 37 & SD & 167 & Tdk Sehat & Ada & $?$ \\
\hline 65. & Yuni & 32 & SLTP & 153 & Sehat & Ada & $?$ \\
\hline 66. & Sabaruddin & 32 & SLTA & 157 & Sehat & Ada & $?$ \\
\hline
\end{tabular}

\subsection{Kelayakan Tenaga Kerja}

Kelayakan memiliki 2 arti. Kelayakan berasal dari kata dasar layak. Kelayakan adalah sebuah homonim karena arti-artinya memiliki ejaan dan pelafalan yang sama tetapi maknanya berbeda. Kelayakan memiliki arti dalam kelas nomina atau kata benda sehingga kelayakan dapat menyatakan nama dari seseorang, tempat, atau semua benda dan segala yang dibendakan. Tenaga kerja merupakan penduduk yang berada dalam usia kerja. Menurut UU No. 13 tahun 2003 Bab I pasal 1 ayat 2 disebutkan bahwa tenaga kerja adalah setiap orang yang mampu melakukan pekerjaan guna menghasilkan barang atau jasa baik untuk memenuhi kebutuhan sendiri maupun untuk masyarakat. Secara garis besar penduduk suatu negara dibedakan menjadi dua kelompok, yaitu tenaga kerja dan bukan tenaga kerja. Penduduk tergolong tenaga kerja jika penduduk tersebut telah memasuki usia kerja. Batas usia kerja yang berlaku di Indonesia adalah berumur 15 tahun - 64 tahun (wikipedia, 2018).

\subsection{Algoritma Naive Bayes}

Naive Bayes merupakan pengklasifikasian dengan metode probabilitas dan statistik yang dikemukakan oleh ilmuwan Inggris Thomas Bayes, yaitu memprediksi peluang di masa depan berdasarkan pengalaman di masa sebelumnya sehingga dikenal sebagai teorema Bayes. Teorema tersebut dikombinasikan dengan "naive" dimana diasumsikan kondisi antar atribut saling bebas [1]. Kelebihan algoritma Naive Bayes Casifier lebih mudah untuk digunakan karena hanya memiliki alur perhitungan yang tidak panjang, hanya memerlukan sejumlah kecil data pelatihan untuk mengestimasi parameter (rata rata dan variansi dari variabel) yang dibutuhkan untuk klasifikasi, dan kokoh terhadap atribut yang tidak relevan. Untuk menyelesaikan metode Naive Bayes dapat dilakukan dengan persamaan-persamaan sebagai berikut [2] : 
$\mathrm{P}(\mathrm{H} \mid \mathrm{X})=\frac{\mathrm{P}(\mathrm{H} \mid \mathrm{X}) \cdot \mathrm{P}(\mathrm{H})}{\mathrm{P}(\mathrm{X})}$

Keterangan:

$\mathrm{X} \quad$ : Data dengan class yang belum diketahui

$\mathrm{H} \quad$ : Hipotesis data merupakan suatu class spesifik

$\mathrm{P}(\mathrm{H} \mid \mathrm{X})$ : Probabilitas hipotesis $\mathrm{H}$ berdasar kondisi X (posteriori probabilitas)

$\mathrm{P}(\mathrm{H}) \quad$ : Probabilitas hipotesis $\mathrm{H}$ (prior probabilitas)

$\mathrm{P}(\mathrm{X} \mid \mathrm{H})$ : Probabilitas $\mathrm{X}$ berdasarkan kondisi pada hipotesis $\mathrm{H}$

$\mathrm{P}(\mathrm{X}) \quad$ : Probabilitas $\mathrm{X}$

Penjabaran lebih lanjut rumus Bayes tersebut dilakukan dengan menjabarkan $(C / X 1 \ldots, X \mathrm{n})$ menggunakan aturan perkalian sebagai berikut.

$$
\begin{aligned}
P(C / x 1, \ldots . ., X n & =P(C) P(x 1, \ldots, x n / C) \\
& =P(C) P(X 1 / C) P(X 2, \ldots, X n / C, X 1) \\
& =(C) P(X 1 / C) P(X 2 / C, X 1) P(X 3, \ldots X n / C, X 1, X 2 \\
& =(C) P(X 1 / C) P(X 2 / C, X 1) P(X 3 / C, X 1, X 2) P(X 4, \ldots, X n / C, X 1, X 2, X 3) \\
& =P(C) P(X 1 / C) P(X 2 / C, X 1) P(X 3 / C, X 1, X 2) \ldots P
\end{aligned}
$$

$(X n / C, X 1, X 2, X 3, \ldots, X n-1$

Dapat dilihat bahwa semakin banyak faktor-faktor yang semakin kompleks yang mempengaruhi nilai probabilitas, maka semakin mustahil untuk mengitung nilai tersebut satu persatu. Akibatnya perhitungan semakin sulit untuk dilakukan, maka disinilah digunakan asumsi independensi yang sangat tinggi, bahwa masingmasing atribut dapat saling bebas. Dengan asumsi tersebuut, diperlukan persamaan (3) :

$$
\begin{aligned}
P(X i \mid X j) & =\frac{P\left(X i \cap X_{j}\right)}{P\left(x_{j}\right)} \\
& =\frac{P(X i) P\left(X_{j}\right)}{P\left(x_{j}\right)} \\
& =P(X i)
\end{aligned}
$$

Untuk $\mathrm{i} \neq \mathrm{j}$, sehingga

$$
P(X i / C, X j)=P(X i / C)
$$

Dari persamaan (3) tersebut dapat di ambil kesimpulan bahwa asumsi independensi membuat syarat perhitungan menjadi lebih sederhana. Selanjutnya penjabaran $(P(C / X 1, \ldots . ., X n)$ dapat disederhanakan menjadi persamaan (4) :

$P(X 2 \mid C) P(X 3 \mid C) \ldots$

$P(C \mid X 1, \ldots, X n=P(X 1 \mid C)$

$$
=\prod_{i=1}^{n} P(X i \mid C)
$$

Keterangan :

$\prod_{i=1}^{n} P(X i \mid C)=$ perkalian ranting antar atribut 
Persamaan (4) merupakan teorema bayes yang kemudian akan digunakan untuk melakukan perhitungan klasifikasi. Untuk klasifikasi dengan data continue atau data angka menggunakan rumus distribusi Gaussian dengan 2 parameter : mean $\mu$ dan varian $\sigma$ :

$P(X i=x i \mid C=c j)=\frac{1}{\sqrt{2 \pi \sigma i j}} \exp \frac{(x i-\mu i j) 2}{2 \sigma \sigma 2 i j}$

\section{Keterangan:}

$\mathrm{P} \quad$ : Peluang

$\mathrm{Xi} \quad$ : Atribut ke i

$\mathrm{Xj} \quad$ : Nilai atribut ke i

C : Kelas yang dicari

$\mathrm{Ci} \quad$ : Sub kelas Y yang dicari

$\mu \quad$ : menyatakan rata-rata dari seluruh atribut

$\sigma \quad$ : Deviasi standar, menyatakan varian dari seluruh atribut

Dalam metode naive bayes diperlukan data latih dan data uji yang ingin diklasifikasikan, dalam naive bayes, semakin banyak data latih yang yang dilibatkan, semakin baik hasil yang prediksi yang diberikan.Menghitung P(Ci) yang merupakan probabilitas prior untuk setiap sub kelas $\mathrm{C}$ yang akan dihasilkan menggunakan persamaan:

$P(c i)=\frac{s i}{s}$

Dimana Si adalah jumlah data training dari kategori $\mathrm{Ci}$, dan s adalah jumlah total data training.Menghitung $\mathrm{P}(\mathrm{Xi} \mid \mathrm{Ci})$ yang merupakan probabilitas posterior $\mathrm{Xi}$ dengan syarat $\mathrm{C}$ menggunakan persamaan (4).

\section{HASIL DAN PEMBAHASAN}

\subsection{Analisa Algoritma Naive Bayes}

Tabel 2. Data Testing

\begin{tabular}{|c|l|c|l|c|c|c|c|}
\hline No & Nama & Usia & Pendidikan & $\begin{array}{c}\text { Tinggi } \\
\text { Badan }\end{array}$ & $\begin{array}{c}\text { Test } \\
\text { Kesehatan }\end{array}$ & $\begin{array}{c}\text { Pengalaman } \\
\text { Kerja }\end{array}$ & Kelayakan \\
\hline 1 & Yosi & 26 & DIPLOMA 3 & 156 & Sehat & Tidak Ada & $?$ \\
\hline 2 & Agus & 26 & SARJANA & 159 & Sehat & Tidak Ada & $?$ \\
\hline 3 & Johan & 25 & SLTP & 155 & TdkSehat & Ada & $?$ \\
\hline 4 & Eka & 24 & DIPLOMA 3 & 167 & Sehat & Ada & $?$ \\
\hline 5 & Cici saragih & 24 & SLTA & 163 & Sehat & Ada & $?$ \\
\hline 6 & Rukia & 39 & SLTA & 160 & Tdk Sehat & Ada & $?$ \\
\hline 7 & Betty & 24 & SLTA & 161 & Sehat & Tidak Ada & $?$ \\
\hline 8 & Anurada & 25 & DIPLOMA 3 & 163 & Sehat & Ada & $?$ \\
\hline 9. & Kristasari & 21 & SLTA & 155 & Sehat & Tidak Ada & $?$ \\
\hline 10 & Esra Yohana & 19 & SLTP & 158 & Sehat & Tidak Ada & $?$ \\
\hline 11 & Fella Indiola & 25 & SLTA & 163 & Sehat & Ada & $?$ \\
\hline 12 & Esti Y & 19 & SLTA & 156 & Sehat & Tidak Ada & $?$ \\
\hline 13 & Amelia & 37 & SLTA & 160 & Sehat & Ada & $?$ \\
\hline 14 & Lenni & 20 & SLTA & 170 & Sehat & Ada & $?$ \\
\hline 15 & Irwan Sari & 37 & SD & 167 & Tdk Sehat & Ada & $?$ \\
\hline
\end{tabular}




\begin{tabular}{|c|l|c|l|c|c|c|c|}
\hline & Nama & Usia & Pendidikan & Tinggi & Test & Pengalaman & Kelayakan \\
\hline 16 & Yuni & 32 & SLTP & 153 & Sehat & Ada & $?$ \\
\hline 17 & Sabaruddin & 32 & SLTA & 157 & Sehat & Ada & $?$ \\
\hline
\end{tabular}

1. Perhitungan Probabilitas Prior (P(Ci))

Dari 49 data latih yang digunakan, diketahui kelas C0 (Tidak layak) sebanyak 14 data, dan kelas C1 (layak) sebanyak 35 data. Perhitungan probabilitas prior kemungkinan tidak layak penentuan calon tenaga kerja, dapat dilakukan dengan persamaan (6) yaitu :

$P(C 0)=\frac{14}{49}=0.286$

Sedangkan perhitungan probabilitas kemungkinan layak yaitu :

$$
P(C 1)=\frac{35}{49}=0.714
$$

2. Perhitungan Probabilitas Posterior $X$ bersyaratC (P(X|Ci))

Untuk menghitung probabilitas variabel Pendidikan dapat dilihat pada Tabel 2. sebagai berikut:

Tabel 3. Probabilitas Pendidikan

\begin{tabular}{|l|c|c|c|c|}
\hline \multirow{2}{*}{ Pendidikan } & “ Jumlah Kejadian Yang di Pilih “ & \multicolumn{2}{c|}{ Probabilitas } \\
\cline { 2 - 5 } & Layak & Tidak Layak & Layak (C1) & Tidak Layak (C0) \\
\hline SD & 0 & 2 & 0 & 0,142857143 \\
\hline SMP & 0 & 5 & 0 & 0,357142857 \\
\hline SMA/SMK & 33 & 6 & 0,942857 & 0,428571429 \\
\hline >D3 & 2 & 1 & 0,057143 & 0,071428571 \\
\hline Jumlah & $\mathbf{3 5}$ & $\mathbf{1 4}$ & $\mathbf{1}$ & $\mathbf{1}$ \\
\hline
\end{tabular}

Probabilitas variabel pendidikan yaitu pada kategori Layak pada tingkat pendidikan SD memiliki probabilitas 0, pada Tingkat SMP memiliki probabilitas 0, tingkat SMA memiliki probabilitas 0.942857, tingkat >D3 memiliki probabilitas 0.057143 . Sehingga jumlah probabilitas Layak yaitu 1. Sedangkan pada kategori Tidak Layak, tingkat pendidikan SD memiliki probabilitas 0.142857143, pada Tingkat SMP memiliki probabilitas 0.357142857 , tingkat SMA memiliki probabilitas 0.428571429 , tingkat $>$ D3 memiliki probabilitas 0.071428571. Sehingga jumlah probabilitas Tidak Layak yaitu 1. Untuk menghitung probabilitas variabel Usia dan variabel lainnya juga dapat dilakukan dengan menggunakan cara yang sama seperti pada tabel 3:

3. Perhitungan Probabilitas Data Uji

Berdasarkan Data Testing pada Tabel 2. dapat dilakukan klasifikasi kedalam kelas Tidak Layak (C0) Penentuan Kelayakan Tenaga Kerja nilai masing-masing kriteria yaitu : 0.07142857, 0,1428571, 0.2142857, 0.8571429, 0,571429.

Kemudian nilai dari masing-masing kriteria tersebut dikalikan $\mathrm{P}(\mathrm{X} \mid \mathrm{C} 0)=\mathrm{P}(\mathrm{XPendidikan}=$ DiplomaIII $\mid \mathrm{C} 0) * \mathrm{P}(\mathrm{Xusia}=26 \mid \mathrm{C} 0) * \mathrm{P}(\mathrm{Xpengalaman}$ Kerja=Tidak Ada $\mid \mathrm{C} 0) * \mathrm{P}(\mathrm{X}$ Test Kesehatan $=$ Sehat $\mid \mathrm{C} 0) * \mathrm{P}(\mathrm{Xtinggi}$ Badan= $156 \mid \mathrm{C} 0))=0.07142857 * 0,1428571 * 0.2142857 * 0.8571429 * 0,571429=0,001071$ 
Untuk menghitung klasifikasi kedalam kelas Layak (C1) Penentuan Kelayakan Tenaga Kerja dengan ketetuan nilai masing-masing kriteria yaitu : $0.057143,0,514286,0.257143,1,0,4$. Kemudian nilai dari masing-masing kriteria tersebut dikalikan

$\mathrm{P}(\mathrm{X} \mid \mathrm{C} 1)=\mathrm{P}(\mathrm{XPendidikan}=$ DiplomaIII $\mid \mathrm{C} 1) * \mathrm{P}(\mathrm{Xusia}=26 \mid \mathrm{C} 1) * \mathrm{P}(\mathrm{Xpengalaman}$ Kerja $=$ Tidak Ada $\mid \mathrm{C} 1) * \mathrm{P}(\mathrm{X}$ Test Kesehatan $=$ Sehat $\mid \mathrm{C} 1) * \mathrm{P}(\mathrm{Xtinggi}$ Badan $=$ $156 \mid C 1))=0.057143 * 0,514286 * 0.257143 * 1 * 0.4=0,003023$

4. Pemaksimalan $\mathrm{P}(\mathrm{X} \mid \mathrm{Ci}) \mathrm{P}(\mathrm{Ci})$

Perhitungan pemaksimal untuk klasifikasi kelas Tidak Layak (CO) adalah dengan cara mengalikan $\mathrm{P}(\mathrm{X} \mid \mathrm{C} 0)$ dengan $\mathrm{P}(\mathrm{CO})$ :

$$
\begin{aligned}
\mathrm{P}(\mathrm{C} 0 \mid \mathrm{X}) & =\mathrm{P}(\mathrm{X} \mid \mathrm{C} 0) \times \mathrm{P}(\mathrm{C} 0) \\
& =0,001071 * 0,28571 \\
& =0,00030599
\end{aligned}
$$

Kemudian untuk kelas Layak (C1) adalah dengan cara mengalikan $\mathrm{P}(\mathrm{X} \mid \mathrm{C} 1)$ dengan $\mathrm{P}(\mathrm{C} 1)$ :

$$
\begin{aligned}
\mathrm{P}(\mathrm{C} 1 \mid \mathrm{X}) & =\mathrm{P}(\mathrm{X} \mid \mathrm{C} 1) \times \mathrm{P}(\mathrm{C} 1) \\
& =0,003023 * 0,71429 \\
& =0,002159121
\end{aligned}
$$

Dari perhitungan di atas dapat dihasilkan nilai $\mathrm{P}(\mathrm{C} 0 \mid \mathrm{X})=0,00030599$, sedangkan nilai $\mathrm{P}(\mathrm{C} 1 \mid \mathrm{X})=0,002159121$. Berdasarkan nilai tersebut dapat di ambil kesimpulan bahwa $\mathrm{P}(\mathrm{C} 0 \mid \mathrm{X})>\mathrm{P}(\mathrm{C} 1 \mid \mathrm{X})$. maka data uji tersebut diklasifikasikan kedalam kelas Layak sebagai calon tenaga kerja. Berikut Tabel Hasil Klasifikasi:

Tabel 4. Hasil Klasifikasi

\begin{tabular}{|l|l|c|c|r|l|}
\hline \multirow{2}{*}{ NO } & \multirow{2}{*}{ NAMA } & \multicolumn{2}{|c|}{ PEMAKSIMALAN } & NILAI MAX & KELAYAKAN \\
\cline { 3 - 4 } & & $\mathrm{P}(\mathrm{X} \mid \mathrm{C} 1)^{*} \mathrm{P}(\mathrm{C} 1)$ & $\mathrm{P}(\mathrm{X} \mid \mathrm{C} 0)^{*} \mathrm{P}(\mathrm{C} 0)$ & & \\
\hline 1. & Yosi & 0,002159121 & 0,00030599 & 0,0021591 & LAYAK \\
\hline 2. & Agus & 0,002159121 & 0,00030599 & 0,0021591 & LAYAK \\
\hline 3. & Johan & 0 & 0,00046749 & 0,0004675 & T. LAYAK \\
\hline 4. & Eka & 0,00579193 & 0,00028049 & 0,0057919 & LAYAK \\
\hline 5. & Cici & 0,102917757 & 0,00673179 & 0,1029178 & LAYAK \\
\hline 6. & Rukia & 0 & 0,00392688 & 0,0039269 & T. LAYAK \\
\hline 7. & Betty & 0,035625404 & 0,00183594 & 0,0356254 & LAYAK \\
\hline 8. & Anurada & 0,006237456 & 0,00112196 & 0,0062375 & LAYAK \\
\hline 9. & Kristasari & 0,018095405 & 0,00229493 & 0,0180954 & LAYAK \\
\hline 10. & Esra & 0 & 0,00382488 & 0,0038249 & T. LAYAK \\
\hline 11. & Fella & 0,102917757 & 0,00673179 & 0,1029178 & LAYAK \\
\hline 12. & Esti & 0,031667018 & 0,00458986 & 0,031667 & LAYAK \\
\hline 13. & Amelia & 0,005717564 & 0,02356126 & 0,0235613 & T. LAYAK \\
\hline 14. & Lenni & 0,084948067 & 0,00420737 & 0,0849481 & LAYAK \\
\hline 15. & Irwan & 0 & 0,00032724 & 0,0003272 & T. LAYAK \\
\hline 16. & Yuni & 0 & 0,00981719 & 0,0098172 & T. LAYAK \\
\hline 17. & Sabaruddin & 0,005717564 & 0,02356126 & 0,0235613 & T. LAYAK \\
\hline
\end{tabular}

Berdasarkan pada gambar 1. dapat diketahui bahwa pada titik berwarna biru (Layak) memiliki banyak node yaitu 10, sedangkan pada titik berwarna merah (Tidak Layak) memiliki hanya 7 node. 


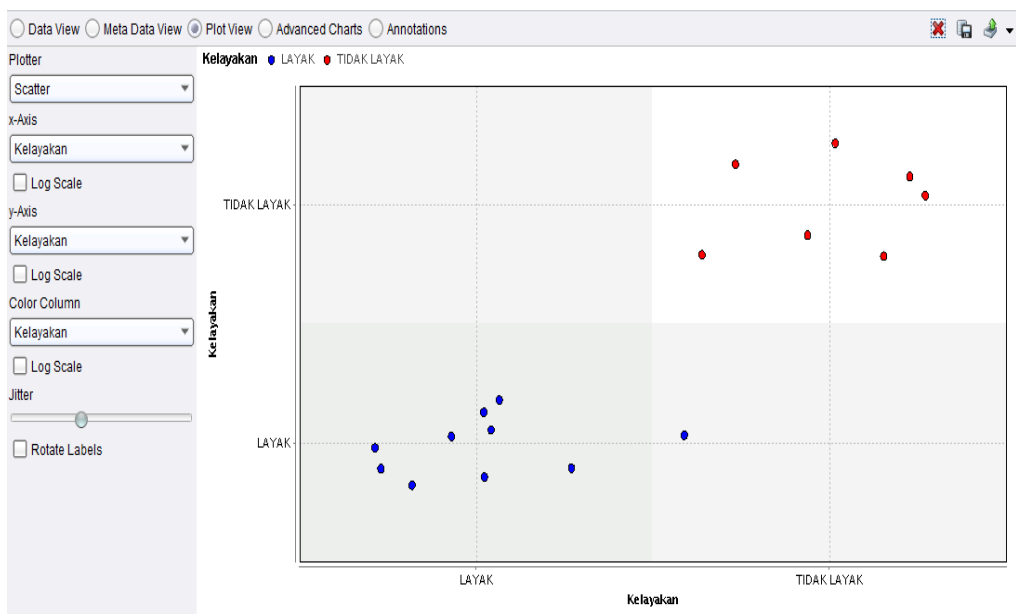

Gambar 1. Grafik klasifikasi Data Testing

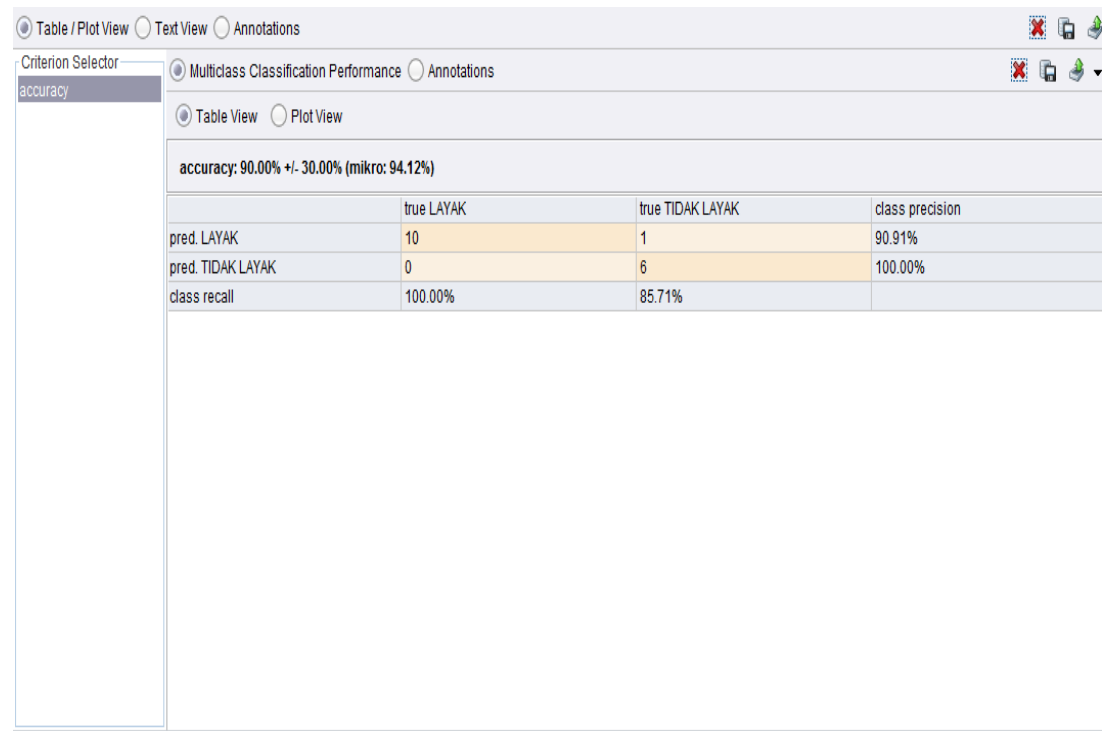

Gambar 2. Nilai Accuracy Performance Data Testing

Keterangan :

1. Jumlah prediksi Layak dan kenyataannya benar Layak adalah 10 record.

2. Jumlah prediksi Tidak Layak dan kenyataannya benar Layak adalah 0 record.

3. Jumlah prediksi Layak dan kenyataannya benar Tidak Layak adalah 1 record.

4. Jumlah prediksi Layak dan kenyataannya benar Layak adalah 6 record.

Pada gambar 4.26. Nilai Accuracy sebesar 90,00\%. class precision pada prediksi Layak memiliki nilai 90,91\%, sedangkan pada prediksi Tidak Layak memiliki nilai $100 \%$. Class recall pada true Layak memiliki nilai 100\%, sedangkan pada true Tidak Layak memiliki nilai $85,71 \%$.

\section{KESIMPULAN}

Berdasarkan pembahasan diatas dapat disimpulkan bahwa :

a. Penerapan Data Mining menggunakan algoritma naïve bayes untuk penentuan kelayakan tenaga kerja Indonesia dengan data uji sebanyak 17 orang dengan 
menggunakan dua kelas. klasifikasi dengan kelas Layak sebanyak 10 orang dan kelas Tidak Layak sebanyak 7orang.

b. Pengujian data pada Rapiminer 5.3 dengan menggunakan metode Naive Bayes berhasil menampilkan dua kelas dari hasil klasifikasi dengan persentase keakuratan sebesar 90,00\%. Dengan class precision pada prediksi Layak memiliki nilai 90,91\%, sedangkan pada prediksi Tidak Layak memiliki nilai 100 $\%$. Class recall pada true Layak memiliki nilai 100\%, sedangkan pada true Tidak Layak memiliki nilai $85,71 \%$.

\section{DAFTAR PUSTAKA}

[1] Syarli and A. A. Muin, "Metode Naive Bayes Untuk Prediksi Kelulusan ( Studi Kasus : Data Mahasiswa Baru Perguruan Tinggi )," J. Ilm. Ilmu Komput., vol. 2, no. 1, p. 5, 2016.

[2] C. Fadlan, S. Ningsih, and A. P. Windarto, "PENERAPAN METODE NAÏVE BAYES DALAM KLASIFIKASI KELAYAKAN KELUARGA PENERIMA BERAS RASTRA," JUTIM, vol. 3, no. 1, pp. $1-8,2018$.

[3] Asrul Ashari, Studi, P., Informatika, T., Muin, Studi, P., \& Informasi, S. (2016). Metode Naive Bayes Untuk Prediksi Kelulusan ( Studi Kasus : Data Mahasiswa Baru Perguruan Tinggi ), 2(1).

[4] Hendini, A. (2016). PEMODELAN UML SISTEM INFORMASI MONITORING PENJUALAN DAN STOK BARANG (STUDI KASUS: DISTRO ZHEZHA PONTIANAK), IV(2), 107-116.

[5] Manalu, E., Sianturi, F. A., \& Manalu, M. R. (2017). PENERAPAN ALGORITMA NAIVE BAYES UNTUK MEMPREDIKSI JUMLAH PRODUKSI BARANG BERDASARKAN DATA PERSEDIAAN DAN JUMLAH PEMESANAN PADA CV . PAPADAN MAMA PASTRIES, 1(2).

[6] Mardi, Y. (2016). Jurnal Edik Informatika Data Mining : Klasifikasi Menggunakan Algoritma C4 . 5. Jurnal Edik Informatika. Jurnal Edik Informatika, V2.i2, 213-219. Retrieved from algorithm; classification; c-4.5

[7] Metisen, B. M., \& Sari, H. L. (2015). Analisis Clustering Menggunakan Metode K-Means dalam Pengelompokkan Penjualan Produk pada Swalayan Fadhila. Jurnal Media Infotama, 11(2), 110-118.

[8] Nurhadi, A. (2015). Klasifikasi Konten Berita Digital Bahasa Indonesia Menggunakan Support Vector Machines ( SVM ) Berbasis Particle Swarm Optimization ( PSO ). Jurnal Bianglala Informatika, 3(2), 1-9. 